\title{
C59T mutation in exon 2 of monocytic leukemia-associated antigen-34 gene indicates a high risk of recurrence of acute myeloid leukemia
}

\author{
BO LEI ${ }^{1}$, YINXIA CHEN ${ }^{1}$, AILI HE ${ }^{1}$, JING LUO ${ }^{1}$, PENGYU ZHANG ${ }^{1}$, FULING ZHOU ${ }^{1}$, \\ JIE LIU $^{1}$, XIN MENG $^{1}$, JING WANG $^{2}$ and WANGGANG ZHANG ${ }^{1}$
}

${ }^{1}$ Department of Hematology, Second Affiliated Hospital, Medical School of Xi'an Jiaotong University, Xi'an, Shanxi 710004;

${ }^{2}$ Department of Neurology, 451 Hospital of People's Liberation Army, Xi'an, Shaanxi 710054, P.R. China

Received February 24, 2016; Accepted February 13, 2017

DOI: $10.3892 / \mathrm{ol} .2017 .6110$

\begin{abstract}
Monocytic leukemia-associated antigen-34 (MLAA-34) is a novel monocytic leukemia-associated antigen and a candidate oncogene. The aim of the present study was to investigate the involvement of the MLAA-34 gene in acute myeloid leukemia (AML). MLAA-34 expression level, chromosome location, gene copy number and single nucleotide polymorphisms (SNPs) of 40 patients with AML and 5 healthy volunteers were analyzed by reverse transcription-polymerase chain reaction, fluorescence in situ hybridization and DNA sequencing. The effects of MLAA-34 mutation on overall survival (OS) and progression-free survival (PFS) of patients with AML were also analyzed. MLAA-34 was significantly upregulated in patients with AML when compared with volunteer controls, and this upregulation was associated with a C59T SNP site located in the second exon of MLAA-34. MLAA-34 was mapped to $13 \mathrm{q} 14.2$ and no translocation was observed in patients with AML. In addition, this SNP site is affinitive to the well-known molecular markers of AML, including Fms-like tyrosine kinase 3 and DNA methyltransferase $3 \mathrm{~A}$, as well as extramedullary lesions, periphery leukocyte numbers, remission and cytogenetic abnormalities of patients with AML. Patients with AML with MLAA-34 C59T mutations had significantly shorter OS and PFS times compared with that of patients without C59T mutations. The present findings indicated that the MLAA-34 C59T mutation was a high-risk factor for recurrence of AML, and may be a candidate target for AML therapy.
\end{abstract}

Correspondence to: Dr Wanggang Zhang, Department of Hematology, Second Affiliated Hospital Medical School of Xi'an Jiaotong University, 157 Xiwu Road, Xi'an, Shaanxi 710004, P.R. China

E-mail: zhangwanggang2030@126.com

Key words: acute myeloid leukemia, monocytic leukemia-associated antigen-34, single nucleotide polymorphism, fluorescence in situ hybridization

\section{Introduction}

Acute myeloid leukemia (AML) is the most common form of acute leukemia in adults (1). AML is a genetically heterogeneous disease which results from the over-proliferation of hematopoietic stem cells and their failure to differentiate, resulting in an uncontrolled accumulation of myeloblasts accumulated in the bone marrow as well as the blood $(2,3)$. Allogeneic hematopoietic stem cell transplantation has been demonstrated to be the most effective therapeutic method for acute leukemia and has been integrated into the standard of care (4). However, its application has so far been limited, offering only incomplete prevention of AML clinical relapse $(5,6)$. Simultaneously, the chemotherapy standard of care has only changed slightly over the previous decades. AML is a clinically devastating disease with a 5 year survival rate of only $25 \%$ in adults (7). It remains associated with high rates of recurrence when treated with conventional regimens (3). Thus, novel and more effective therapies that may reduce the risk of relapse following chemotherapy or stem cell transplantation are required $(5,8)$.

Previous studies have indicated that AML-associated antigens may be used as more specific and effective targets for immunotherapy (8), and may represent a promising novel treatment option to improve the outcomes of patients with $\operatorname{AML}(8,9)$. Thus far, dozens of tumor (leukemia)-associated antigens, including hyaluronan-mediated motility receptor/cluster of differentiation 168, M-phase phosphoprotein 11, proteinase 3, Wilms' tumor 1, tumor-associated antigen preferentially expressed antigen in melanoma, oncofectal antigen-immature laminin receptor protein, B-cell lymphoma-2, chronic myeloid leukemia (CML) 28 and CML66, survivin, breakpoint cluster region-abelson murine leukemia, fusion transcript which results from t $(6 ; 9 ; \mathrm{p} 23 ; \mathrm{q} 34$; DEK-CAN), protein which represents promyelocytic leukemia-retinoic acid receptor (PML-RAR), runt-related transcription factor 1-myeloid translocation gene 8 (8) and fms related tyrosine kinase 3 (10) have been characterized in patients with AML, however, novel and more specific antigens remain rare.

The monocytic leukemia-associated antigen-34 (MLAA-34) gene (GeneBank no. AY288977.2) is one of the novel identified leukemia-associated antigens and a candidate 
oncogene $(5,9)$. As a novel splice variant of calcium binding protein 39-like (CAB39L), MLAA-34 exclusively reacts with sera from patients with allogeneic leukemia but not with normal donor sera $(5,8,11,12)$. In addition, MLAA-34 has been indicated to be a potent anti-apoptotic factor associated with carcinogenesis or progression of AML (5). Downregulation of MLAA-34 expression significantly suppresses the proliferation and increases the spontaneous apoptosis of U937 cells in vitro $(5,12)$. Additional studies uncovered that MLAA-34 may be involved in cell apoptosis through interaction with the Ras, Wnt, calcium and chemokine signaling pathways in U937 cells $(5,9,12)$. It has been indicated that 13 of the annotated proteins (PGK1, GAPDH, CRMP1, TBK-1, SEPT7, CLTC, PPP2CA, SOD2, PARK7, HSPA9, TXN, ESR1 and YWHAE) may interact with MLAA-34 and be directly involved in carcinogenesis (12).

Previous studies have indicated that MLAA-34 may be a potential candidate for the early diagnosis and therapeutic application of AML $(5,9)$. However, the association between its expression level and single nucleotide polymorphisms (SNPs) in the diagnosis and prognosis of AML remains unclear. Thus, in the present study, MLAA-34 expression was investigated by reverse transcription-quantitative polymerase chain reaction (RT-qPCR), gene mutation by SNP, and associations with the diagnosis variables. In addition, MLAA-34 gene expression in patients with AML and healthy donors was examined by fluorescence in situ hybridization (FISH).

\section{Materials and methods}

Patients and sample selection. In the present study, 40 patients with AML in different clinical stages were enrolled from the Department of Hematology of the Second Affiliated Hospital of Xi'an Jiaotong University (Xi'an, China) between October 2011 and October 2014, and 5 healthy donors were assayed. The subtypes of all the patients with AML were determined according to the French-American-British (FAB) classification (5) and the relevant clinical data records are listed in Table I. Conventional and molecular cytogenetic analysis, as well as other relevant clinical information, was also investigated in the protocol. Samples of peripheral blood and bone marrow (3 $\mathrm{ml}$ from each donor) were collected into a syringe with heparin $(0.3 \mathrm{ml})$ for use in MLAA-34 mRNA expression level and MLAA-34 gene mutation or FISH assays, respectively. The present study was approved by the Ethics Committee of the School of Medicine, Xi'an Jiaotong University, and was conducted in accordance with the Declaration of Helsinki. Informed consent was obtained from all study donors.

Protocols and therapies. Patients with AML were treated according to the protocols and therapies which were described in a previously published study (9).

RNA extraction, cDNA synthesis and RT-qPCR. Total RNA was extracted from mononuclear cells by TRIzol (Gibco; Thermo Fisher Scientific, Inc., Waltham, MA, USA) according to the standard protocol. The extracted RNA of $1 \mu \mathrm{l}$ (about $2 \mu \mathrm{g}$ ) added to each lane was verified for integrity by $1.5 \%$ agarose gel electrophoresis and estimated for purity at 260 and $280 \mathrm{~nm}$ wavelengths, as determined by an ultraviolet spectrophotometer (ZF1 Shanghai Jia Peng Technology Co., Ltd., Shanghai, China), samples were used for cDNA synthesis with the first strand cDNA synthesis kit (Takara Biotechnology Co., Ltd., Dalian, China) according to the manufacturer's protocol.

TaqMan-based PCR technology was performed on an ABI 5700 FAST instrument (Applied Biosystems; Thermo Fisher Scientific, Inc.) in a total volume of $50 \mu 1$. MLAA-34 primers as well as the TaqMan probe sequence were as follows: (forward, 3'-AAGCCGGAGAACCTG AAACTC-5' and reverse, 3'-TGAGGACTGGCCACA AACAC-5') and probe [FAM-TGA-GAACCTCCTTCG GGATAAAAG-tetramethylrhodamine (TAMRA)] (DaAn Gene Co., Ltd., Guangzhou, China). Expression of $\beta$-actin was used as a reference gene control. Primers and probes for $\beta$-actin were as follows: Forward, 3'-TCCTTCCTG GGTATGGAATC-5' and reverse, 3'-GCACTGTGTTGGCAT AGAGG-5'; probe, FAM-CGGATGTCAACGTCACACACTT CATGA-TAMRA (DaAn Gene Co., Ltd.). The reaction procedure was performed as follows: The reaction was performed in triplicate with a total volume of $50 \mu \mathrm{l}$ supplemented with $10 \mu 1$ 5x TaqMan Universal PCR buffer, $1.0 \mu 1$ (300 nM) forward/reverse primer, $1 \mu \mathrm{l}(200 \mathrm{nM})$ probe, $1 \mu \mathrm{l} \mathrm{dNTP}$, $1 \mu 1$ Taq DNAase, $5 \mu 1$ cDNA and $30 \mu 1$ nuclease-free water (Shanghai GeneCore BioTechnologies Co., Ltd., Shanghai, China). PCR protocol was performed as follows: $93^{\circ} \mathrm{C}$ for $2 \mathrm{~min}, 93^{\circ} \mathrm{C}$ for $30 \mathrm{sec}, 55^{\circ} \mathrm{C}$ for $1 \mathrm{~min}$ for 40 cycles. The cycle threshold (CT) was determined automatically. The samples without DNA were routinely included as a no template control $\left(\mathrm{H}_{2} \mathrm{O}\right)$. Relative quantification of the MLAA-34 gene was conducted with three independent experiments by the $2^{-\Delta \Delta \mathrm{Cq}}$ method as described in a previous study (9).

DNA sequence analysis gene mutation for exons. Genomic DNA was extracted from peripheral blood using the QIAamp DNA blood kit (Qiagen GmbH, Hilden, Germany) according to the manufacturer's protocol, and then stored at $-20^{\circ} \mathrm{C}$ until use. Primers for 12 exons of the MLAA-34 gene were designed with Primer Express Software Version 2.0 (Application Binary Interface of China Branch Office, Shanghai, China) and are listed in Table II. Simultaneously, primers used for genes which are closely associated with AML, including FMS-like tyrosine kinase 3 (Flt3), DNA methyl-transferase 3A (DNMT3A), c-ki, CCAAT-enhancer-binding protein $\alpha(\mathrm{CEBP} \alpha)$ and nucleophosmin-1 (NMP1), were synthesized and are listed as follows: FLT3 forward 5'-GCAATTTAGGTATGAAAGCCAGC-3 and reverse 5-CTTTCAGCATTTTGACGGCAACC-3'; DNMT3a forward 5'-CTGCTGTGTGGTTAGACG-3' and reverse 5'-TATTTCCGCCTCTGTGGTTT-3'; NMP1 forward NMP1F 5'-TCGGGAGATGAAGTTGGAAG-3' and reverse 5'-AAC ATTTATCAAACACGGTAG-3'; C-KIT (exon 17) forward 5'-CAGCCAGAAATATCCTCCTTACT-3' and reverse 5'-TGT CAAGCAGAGAATGGGTACTC-3'; CEBPA: PP1F 5'-TCG CCATGCCGGGAGAACTCTAAC-3' (nucleotides 120-143) and PP1R 5'-CTGGTAAGGGAAGAGGCCGGCCAG-3' (nucleotides 692-669), PP2F 5'-CCGCTGGTGATCAAGCAG GA-3' (nucleotides 615-634) and PP2R 5'-CACGGTCTGGGC AAGCCTCGAGAT-3' (nucleotides 1317-1294). All samples were genotyped using PCR and direct sequencing. PCR amplification was performed using the Takara Ex Taq kit (Takara 
Table I. Clinical characteristics and MLAA-34 expression levels of patients with acute myeloid leukemia, treated by standard chemotherapy.

\begin{tabular}{|c|c|c|c|c|c|c|c|c|}
\hline Sex & $\begin{array}{l}\text { Age } \\
\text { (years) }\end{array}$ & $\begin{array}{l}\text { Relative } \\
\text { MLAA-34 } \\
\text { level }\end{array}$ & $\begin{array}{c}\text { Positive } \\
\text { response to } \\
\text { chemotherapy }\end{array}$ & $\begin{array}{l}\text { Leukocyte } \\
\text { number } \\
\left(\geq 50 \times 10^{9} / 1\right)\end{array}$ & $\begin{array}{l}\text { Extra- } \\
\text { medullary } \\
\text { lesions }\end{array}$ & $\begin{array}{l}\text { Abnormal } \\
\text { karyotype }\end{array}$ & $\begin{array}{l}\text { MLAA-34 } \\
\text { mutation }\end{array}$ & $\begin{array}{l}\text { Risk } \\
\text { strati- } \\
\text { fication }\end{array}$ \\
\hline M & 58 & 331.00 & $\mathrm{~N}$ & Y & $\mathrm{N}$ & Y & - & IR \\
\hline M & 35 & 22.40 & Y & $\mathrm{N}$ & $\mathrm{N}$ & $\mathrm{Y}$ & - & IR \\
\hline $\mathrm{F}$ & 45 & 128.00 & Y & $\mathrm{N}$ & $\mathrm{N}$ & $\mathrm{N}$ & - & IR \\
\hline M & 65 & 9.69 & Y & $\mathrm{N}$ & $\mathrm{N}$ & $\mathrm{N}$ & - & LR \\
\hline $\mathrm{F}$ & 36 & 774.00 & $\mathrm{~N}$ & $\mathrm{Y}$ & $\mathrm{N}$ & $\mathrm{Y}$ & + & HR \\
\hline M & 47 & 37.60 & $\mathrm{Y}$ & $\mathrm{N}$ & $\mathrm{N}$ & $\mathrm{Y}$ & - & IR \\
\hline M & 28 & 4380.00 & $\mathrm{~N}$ & $\mathrm{~N}$ & $\mathrm{~N}$ & $\mathrm{Y}$ & + & HR \\
\hline $\mathrm{F}$ & 66 & 55.40 & Y & $\mathrm{N}$ & $\mathrm{N}$ & $\mathrm{Y}$ & - & HR \\
\hline $\mathrm{F}$ & 54 & 5560.00 & $\mathrm{~N}$ & $\mathrm{Y}$ & Y & $\mathrm{Y}$ & + & HR \\
\hline M & 42 & 221.00 & $\mathrm{~N}$ & $\mathrm{~N}$ & $\mathrm{~N}$ & $\mathrm{~N}$ & - & IR \\
\hline $\mathrm{F}$ & 18 & 88.70 & $\mathrm{Y}$ & $\mathrm{N}$ & $\mathrm{N}$ & $\mathrm{Y}$ & - & LR \\
\hline M & 70 & 1120.00 & $\mathrm{~N}$ & $\mathrm{Y}$ & $\mathrm{N}$ & $\mathrm{Y}$ & + & HR \\
\hline $\mathrm{F}$ & 39 & 8.82 & $\mathrm{Y}$ & $\mathrm{N}$ & $\mathrm{N}$ & $\mathrm{Y}$ & - & IR \\
\hline $\mathrm{F}$ & 21 & 11.20 & Y & $\mathrm{N}$ & $\mathrm{N}$ & $\mathrm{N}$ & - & IR \\
\hline $\mathrm{F}$ & 28 & 886.00 & $\mathrm{~N}$ & Y & $\mathrm{N}$ & $\mathrm{Y}$ & + & IR \\
\hline $\mathrm{F}$ & 54 & 7.85 & Y & $\mathrm{N}$ & $\mathrm{N}$ & $\mathrm{N}$ & - & IR \\
\hline M & 64 & 11.20 & Y & $\mathrm{N}$ & $\mathrm{N}$ & $\mathrm{Y}$ & - & IR \\
\hline M & 35 & 101.00 & $\mathrm{~N}$ & $\mathrm{~N}$ & $\mathrm{Y}$ & $\mathrm{Y}$ & - & IR \\
\hline $\mathrm{F}$ & 59 & 2230.00 & $\mathrm{~N}$ & $\mathrm{~N}$ & $\mathrm{~N}$ & $\mathrm{Y}$ & + & HR \\
\hline M & 33 & 362.00 & Y & Y & $\mathrm{N}$ & $\mathrm{Y}$ & - & HR \\
\hline M & 31 & 99.40 & Y & $\mathrm{N}$ & $\mathrm{N}$ & $\mathrm{Y}$ & - & IR \\
\hline M & 42 & 3850.00 & $\mathrm{~N}$ & $\mathrm{Y}$ & $\mathrm{N}$ & $\mathrm{Y}$ & + & IR \\
\hline M & 52 & 452.00 & Y & $\mathrm{N}$ & $\mathrm{N}$ & $\mathrm{N}$ & - & IR \\
\hline M & 31 & 66.20 & $\mathrm{~N}$ & $\mathrm{~N}$ & $\mathrm{~N}$ & $\mathrm{Y}$ & - & IR \\
\hline M & 19 & 537.00 & $\mathrm{~N}$ & $\mathrm{Y}$ & $\mathrm{Y}$ & $\mathrm{Y}$ & + & HR \\
\hline M & 23 & 7.98 & $\mathrm{Y}$ & $\mathrm{N}$ & $\mathrm{N}$ & $\mathrm{N}$ & - & HR \\
\hline M & 24 & 1.01 & $\mathrm{Y}$ & $\mathrm{N}$ & $\mathrm{N}$ & $\mathrm{Y}$ & - & IR \\
\hline M & 31 & 886.00 & $\mathrm{~N}$ & $\mathrm{~N}$ & $\mathrm{~N}$ & $\mathrm{Y}$ & + & HR \\
\hline M & 25 & 2240.00 & $\mathrm{~N}$ & $\mathrm{Y}$ & $\mathrm{Y}$ & $\mathrm{Y}$ & + & IR \\
\hline M & 37 & 9.66 & Y & $\mathrm{N}$ & $\mathrm{N}$ & $\mathrm{N}$ & - & LR \\
\hline $\mathrm{F}$ & 39 & 8.87 & Y & $\mathrm{N}$ & $\mathrm{N}$ & $\mathrm{Y}$ & - & IR \\
\hline $\mathrm{F}$ & 24 & 458.00 & $\mathrm{~N}$ & $\mathrm{~N}$ & $\mathrm{~N}$ & $\mathrm{Y}$ & + & HR \\
\hline $\mathrm{F}$ & 26 & 10.80 & $\mathrm{Y}$ & $\mathrm{N}$ & $\mathrm{N}$ & $\mathrm{Y}$ & - & IR \\
\hline M & 33 & 238.00 & $\mathrm{~N}$ & $\mathrm{Y}$ & $\mathrm{Y}$ & $\mathrm{Y}$ & + & HR \\
\hline $\mathrm{F}$ & 35 & 8.86 & Y & $\mathrm{N}$ & $\mathrm{N}$ & $\mathrm{N}$ & - & IR \\
\hline $\mathrm{F}$ & 43 & 8.84 & $\mathrm{~N}$ & $\mathrm{~N}$ & $\mathrm{~N}$ & $\mathrm{Y}$ & - & IR \\
\hline M & 12 & 7.96 & $\mathrm{Y}$ & $\mathrm{N}$ & $\mathrm{N}$ & $\mathrm{N}$ & - & LR \\
\hline $\mathrm{F}$ & 30 & 7.88 & $\mathrm{~N}$ & $\mathrm{~N}$ & $\mathrm{~N}$ & $\mathrm{Y}$ & - & IR \\
\hline $\mathrm{F}$ & 40 & 10.50 & $\mathrm{~N}$ & $\mathrm{~N}$ & $\mathrm{~N}$ & $\mathrm{Y}$ & - & IR \\
\hline $\mathrm{F}$ & 35 & 2.21 & $\mathrm{Y}$ & $\mathrm{N}$ & $\mathrm{N}$ & $\mathrm{N}$ & - & HR \\
\hline \multicolumn{9}{|c|}{ Normal control } \\
\hline $\mathrm{F}$ & 35 & 0.00150 & - & $\mathrm{N}$ & $\mathrm{N}$ & $\mathrm{N}$ & & \\
\hline M & 26 & 0.00885 & - & $\mathrm{N}$ & $\mathrm{N}$ & $\mathrm{N}$ & & \\
\hline $\mathrm{F}$ & 37 & 0.00042 & - & $\mathrm{N}$ & $\mathrm{N}$ & $\mathrm{N}$ & & \\
\hline M & 24 & 0.00135 & - & $\mathrm{N}$ & $\mathrm{N}$ & $\mathrm{N}$ & & \\
\hline $\mathrm{F}$ & 29 & 0.00100 & - & $\mathrm{N}$ & $\mathrm{N}$ & $\mathrm{N}$ & & \\
\hline
\end{tabular}

MLAA-34, monocytic leukemia-associated antigen-34; -, no mutation in MLAA-34 exon 2; +, mutation in MLAA-34 exon 2; LR, low risk; IR, intermediate risk; HR, high risk; M, male; F, female. 
Table II. Primers of 12 exons for monocytic leukemia-associated antigen-34.

\begin{tabular}{|c|c|c|c|}
\hline $\begin{array}{l}\text { Exon } \\
\text { no. }\end{array}$ & $\begin{array}{l}\text { Product } \\
\text { length }\end{array}$ & Forward primer & Reverse primer \\
\hline 1 & 68 & 5'-CAGGCCGACCTACCTAAACC-3' & 5'-CACCATTCCTCGCTCTCTCT-3' \\
\hline 2 & 138 & 5'-CTTGCAGCTGTACATTGAGACC-3' & 5'-GAAAACCCATGCCTGCTAGA-3' \\
\hline 3 & 76 & 5'-TTGAAAGGTCTGCCACTTGA-3' & 5'-GGGAGGAATTCAGGCTCTCT-3' \\
\hline 4 & 138 & 5'-AAGCAAGGCTTGGAATCTGA-3' & 5'-AАССТСТССТАGTAACAGCAATTCA-3' \\
\hline 5 & 142 & 5'-AAATTTGGCATAAAACTTGAAACT-3' & 5'-GTTGCATAAAACCTGAAATCAAC-3' \\
\hline 6 & 165 & 5'-TCCCCTCACTGTTTTTGTTTG-3' & 5'-GTTTGGCTTTTTGCTTTTGT-3' \\
\hline 7 & 119 & 5'-TGCAAGCACAGCTTGTTAGG-3' & 5'-TGCAAAGAAAGGATTTTGCTG-3' \\
\hline 8 & 169 & 5'-CAGTGGATATTGAATGAATCGTG-3' & 5'-CAGACTGGCCTCATAGACTGC-3' \\
\hline 9 & 60 & 5'-ATTTTGTGGCGCAAATGAA-3' & 5'-CGAAGAGATGTGAAAAAGGTGA-3' \\
\hline 10 & 66 & 5'-GTCCCCCAGTGTCTTCACAT-3' & 5'-AGCAGGACAGGACACTTACATT-3' \\
\hline 11 & 144 & 5'-TTGCTTTTATGCCTGTGCTTT-3' & 5'-TGGGCATTCATTAAGATAACTCTG-3' \\
\hline 12 & 342 & 5'-TCAGGGGCTTCTACGCATTA-3' & 5'-GGGCTCACATCTGCAAGTTA-3' \\
\hline
\end{tabular}

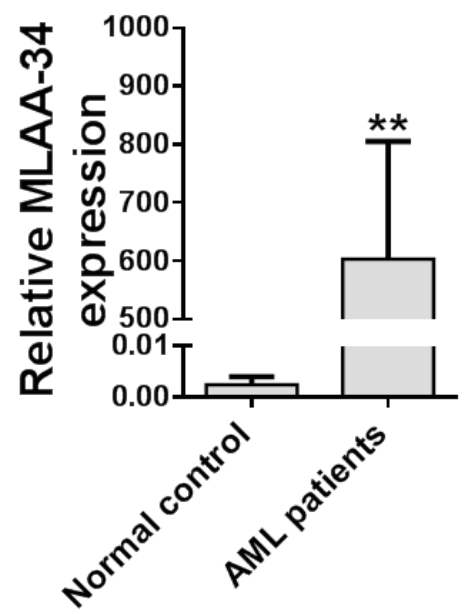

Figure 1. MLAA-34 gene is upregulated in patients with AML. Total mRNA was extracted from leukocytes of 40 patients with AML and 5 healthy volunteers, and MLAA-34 gene expression was detected by reverse transcription-polymerase chain reaction and normalized to $\beta$-actin gene. ${ }^{* *} \mathrm{P}<0.01$ vs. control. MLAA-34, monocytic leukemia-associated antigen-34; AML, acute myeloid leukemia.

Biotechnology Co., Ltd.) according to the manufacturer's protocol. The PCR thermocycling conditions were: $95^{\circ} \mathrm{C}$ for $3 \mathrm{~min} ; 32$ cycles of $95^{\circ} \mathrm{C}$ for $30 \mathrm{sec} ; 58^{\circ} \mathrm{C}$ for $30 \mathrm{sec} ; 72^{\circ} \mathrm{C}$ for $1 \mathrm{~min}$; and a final extension at $72^{\circ} \mathrm{C}$ for $10 \mathrm{~min}$. Subsequent to purifying the PCR products with an AxyPrep DNA purification kit (Qiagen $\mathrm{GmbH}$ ), direct sequencing was performed on the ABI 5700 DNA Analyzer using a Big Dye Terminator kit v3.1 (Applied Biosystems; Thermo Fisher Scientific, Inc.) with the corresponding forward primer as the sequencing primer. The analytical approach, which applied the sequencing of data by Vector NTI 8.0 analysis software (Invitrogen; Thermo Fisher Scientific, Inc.), focused on base pair substitutions (SNPs).

FISH. Metaphase chromosomes were prepared from the cultivated bone marrow cells according to the method described previously (13). R-banding of chromosomes stained with Giemsa-staining was performed according to the standard
A

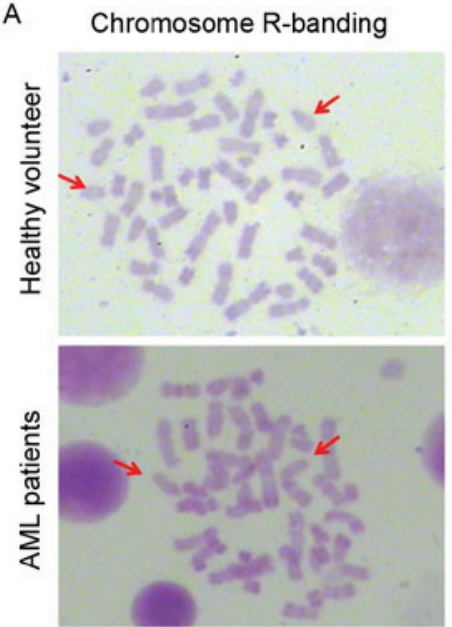

B
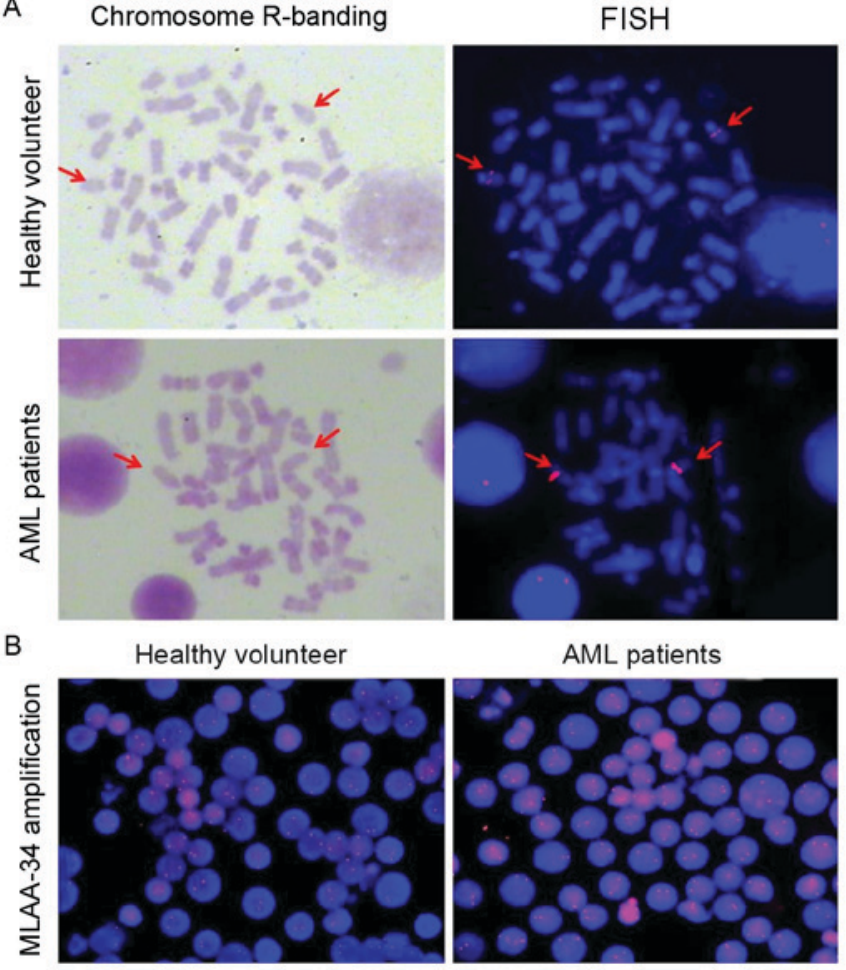

AML patients

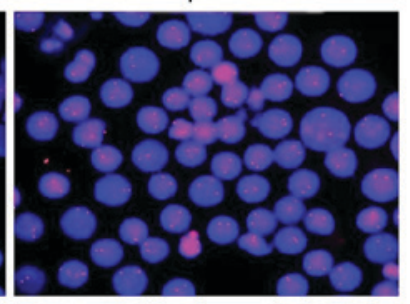

Figure 2. MLAA-34 gene localization with FISH. (A) Metaphase chromosomes were prepared from bone marrow blast monocytes of 40 patients with AML and 5 healthy volunteers, and MLAA- 34 gene expression was detected by FISH. The red arrows indicate the no. 13 chromosomes (magnification, x100). (B) Leukocytes were separated from 40 patients with AML and 5 healthy volunteers and MLAA-34 gene amplification was determined by FISH (magnification, x100). MLAA-34, monocytic leukemia-associated antigen-34; FISH, fluorescent in situ hybridization; AML-M5, acute monocytic leukemia.

procedures and was analyzed according to the International System for Human Cytogenetic Nomenclature 2013 using a light microscope and magnification, x100 (Olympus Corporation, Tokyo, Japan). FISH was performed on metaphase cells of bone marrow samples using a MLAA-34 and 
A

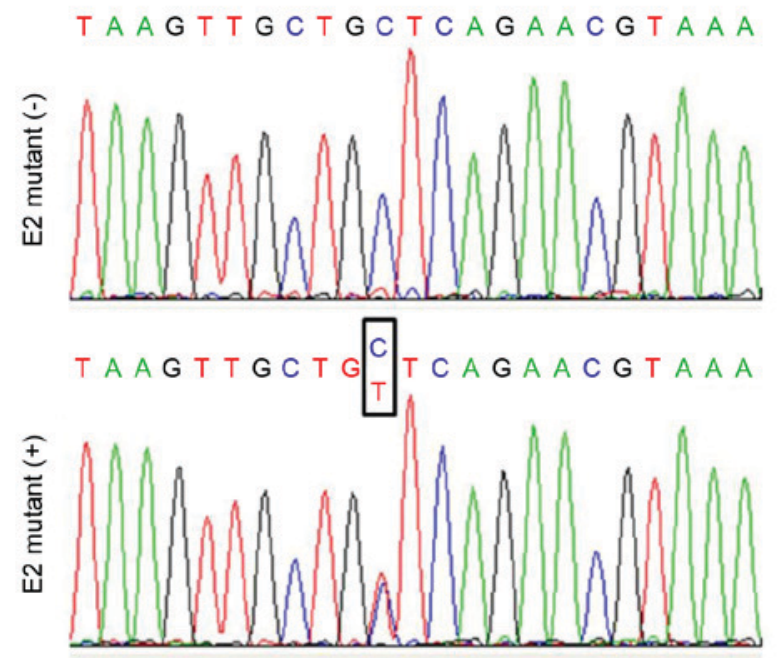

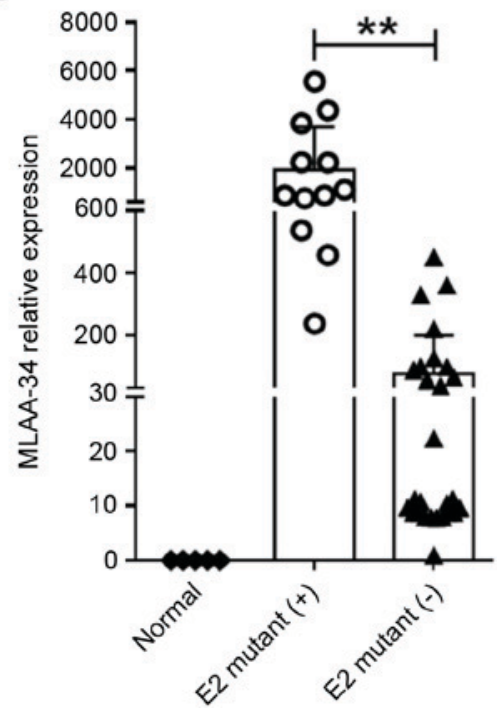

Figure 3. MLAA-34 contains a single nucleotide polymorphism site in patients with acute myeloid leukemia. (A) Two genotypes and sequence comparisons of MLAA-34 gene in homo sapiens. A representative sequencing map from wild-type homozygous CC and mutant heterozygous CT is depicted. (B) MLAA-34 mRNA expression levels were detected by reverse transcription-polymerase chain reaction from E2-mutant $(+)$ and E2-mutant $(-)$ patients. ${ }^{* *} \mathrm{P}<0.01$, with comparisons indicated by lines. MLAA-34, monocytic leukemia-associated antigen-34; E2, exon 2.

RB1 probes for chromosome 13 labeled in red spectrums, provided by An Biping Pharmaceutical Co., Ltd. (Guangzhou, China, http://www.gzlbp.com/). The RB1 probe located at chromosome $13 \mathrm{q} 14$ and labeled in green spectrums was used to confirm MLAA-34 location. The clone numbers of RB1 probe for FISH were RP11-755M4 (chr13:113686037-113853591 bp), CTD-3019N20 (chr13:113755798-114014009 bp), CTD-2147J22 (chr13:114010132-114154734 bp) and RP11-281G7 (chr13:114081588-114285555 bp), respectively. The clone numbers of MLAA-34 for FISH were CTD-2503J7 (chr13: 49250000-49400000 bp) and RP11-803H8 (chr13: 49450000-49600000 bp). Nuclei were counterstained with DAPI (Vysis; Abbott Laboratories, Abbott Park, IL, USA) and signals from 200 nuclei were counted under a fluorescent microscope of magnification, x100. All FISH procedures were performed according to the manufacturer's protocol (An Biping Pharmaceutical Co., Ltd.).

Statistical analysis. Statistical analyses were performed using SPSS version 13.0 software (SPSS, Inc., Chicago, IL, USA). $\mathrm{P}<0.05$ was considered to indicate a statistically significant difference. The $\chi^{2}$ test was applied for baseline clinical variables between groups for categorical data and the significance of difference of homologous chromosomes signals. The probabilities of OS and PFS were estimated with the Kaplan-Meier method. The Cox model and regression analysis were used to analyze the effect of exon 2 (E2) mutation in patients with AML.

\section{Results}

MLAA-34 is upregulated in patients with $A M L$. In order to investigate the function of MLAA-34 in AML, the expression level of MLAA-34 was detected in 40 patients with AML and 5 healthy volunteers, and the results demonstrated that MLAA-34 was significantly upregulated in 40 patients with
AML when compared with healthy volunteers (Fig. 1; Table I). When all the patients received standard chemotherapy, it was evident that the patients with increased MLAA-34 levels had poor or no response to the treatment (Table I). In addition, MLAA-34 mRNA was associated with peripheral white blood cell (WBC) numbers and was prone to overexpression in the high-WBC group (WBC count, $\geq 50 \times 10^{9} / 1$ ) compared with the low-WBC group (WBC count, $<50 \times 10^{9} / 1$ ). Of the 40 patients with AML, abnormal karyotypes were observed in 29 patients (Table I). No significant differences were observed when the subjects were categorized according to age and sex.

MLAA-34 is mapped to 13 q14.2 and there is no translocation in patients with AML. FISH was used to determine whether there was a difference in MLAA-34 localization and gene copy number between patients with AML and healthy controls. The MLAA-34 gene was localized at chromosome 13q14.2 (Fig. 2A). No differences were observed for MLAA-34 gene location between healthy volunteers and patients with AML. To confirm this data, the tumor suppressor gene retinoblastoma (RB1), located at chromosome $13 \mathrm{q} 14$, was selected as a positive control. The results revealed that RB1 and MLAA-34 were co-localized (data not shown). In addition, the fluorescence intensity of patients with AML was relatively increased compared with that of healthy controls, but no significant differences were observed between patients with AML and healthy controls (Fig. 2B). This indicated that the MLAA-34 gene copy number of patients with AML was inconsistent with that of normal controls.

MLAA-34 contains a C59T SNP site in patients with AML. To uncover the mechanism for MLAA-34 overexpression, genomic DNA samples were prepared from 40 patients with AML and 5 healthy controls, and all 12 exons of the MLAA-34 gene were amplified by PCR. PCR products were genotyped and a SNP site was identified in 12 acute mynocytic leukemia (AML-M5) patients (Table I, Fig. 3A). In these patients with 
Table III. Comparisons of the MLAA-34 gene mutations in subgroups stratified by genotypes of Flt3, DNMT3A, C-kit, CEBPA and NPM1 in the control and exposed groups.

\begin{tabular}{|c|c|c|c|c|}
\hline Variables & $\begin{array}{c}\text { MLAA-34 } \\
\text { Mutation (-), } \\
\text { n (\%) }\end{array}$ & $\begin{array}{c}\text { MLAA-34 } \\
\text { Mutation (+), } \\
\text { n (\%) }\end{array}$ & OR $(95 \% \mathrm{CI})^{\mathrm{a}}$ & P-value \\
\hline Flt3 (-) & $27(96.4)$ & $6(50.0)$ & & \\
\hline Flt3 (+) & $1(3.6)$ & $6(50.0)$ & $27.000(2.722-267.796)$ & 0.000 \\
\hline DNMT3A (-) & $26(92.9)$ & $7(58.3)$ & & \\
\hline DNMT3A (+) & $2(7.1)$ & $5(41.7)$ & $9.286(1.475-58.467)$ & 0.008 \\
\hline C-kit (-) & $25(89.3)$ & $10(83.3)$ & & \\
\hline C-kit (+) & $3(10.7)$ & $2(16.7)$ & $1.667(0.241-11.525)$ & 0.602 \\
\hline $\operatorname{CEBP}(-)$ & $22(78.6)$ & $11(91.7)$ & & \\
\hline $\operatorname{CEBP}(+)$ & $6(21.4)$ & $1(8.3)$ & $0.333(0.036-3.123)$ & 0.318 \\
\hline NPM1 (-) & $22(78.6)$ & $12(100.0)$ & & \\
\hline NPM1 (+) & $6(21.4)$ & $0(0.0)$ & $0.786(0.648-0.953)$ & 0.082 \\
\hline Extramedullary disease (-) & $27(96.4)$ & $8(66.7)$ & & \\
\hline Extramedullary disease (+) & $1(3.6)$ & $4(33.3)$ & $13.500(1.315-138.615)$ & 0.009 \\
\hline Leukocyte $<50 \times 10^{9}$ & $25(89.3)$ & $5(41.7)$ & & \\
\hline Leukocyte $\geq 50 \times 10^{9}$ & $3(10.7)$ & $7(58.3)$ & $11.667(2.221-61.278)$ & 0.001 \\
\hline Remission (+) & $20(71.4)$ & $0(0.0)$ & & \\
\hline Remission (-) & $8(28.6)$ & $12(100.0)$ & $0.286(0.159-0.513)$ & 0.000 \\
\hline Abnormal karyotype (-) & $10(35.7)$ & $0(0.0)$ & & \\
\hline Abnormal karyotype (+) & $18(64.3)$ & $12(100.0)$ & $0.643(0.488-0.847)$ & 0.017 \\
\hline Male & $15(53.6)$ & $7(58.3)$ & & \\
\hline Female & $13(46.4)$ & $5(41.7)$ & $0.824(0.210-3.234)$ & 0.781 \\
\hline
\end{tabular}

${ }^{\mathrm{a}} \chi^{2}$ test for comparison between two groups; ${ }^{\mathrm{b}}$ Asymp. significance (two-sided). MLAA-34, monocytic leukemia-associated antigen-34; Flt3, FMS-related tyrosine kinase 3; DNMT3A, DNA methyl-transferase 3A; CEBPA, CCAAT-enhancer-binding protein; NPM1, nucleophosmin-1; CI, confidence interval; OR, odds ratio.
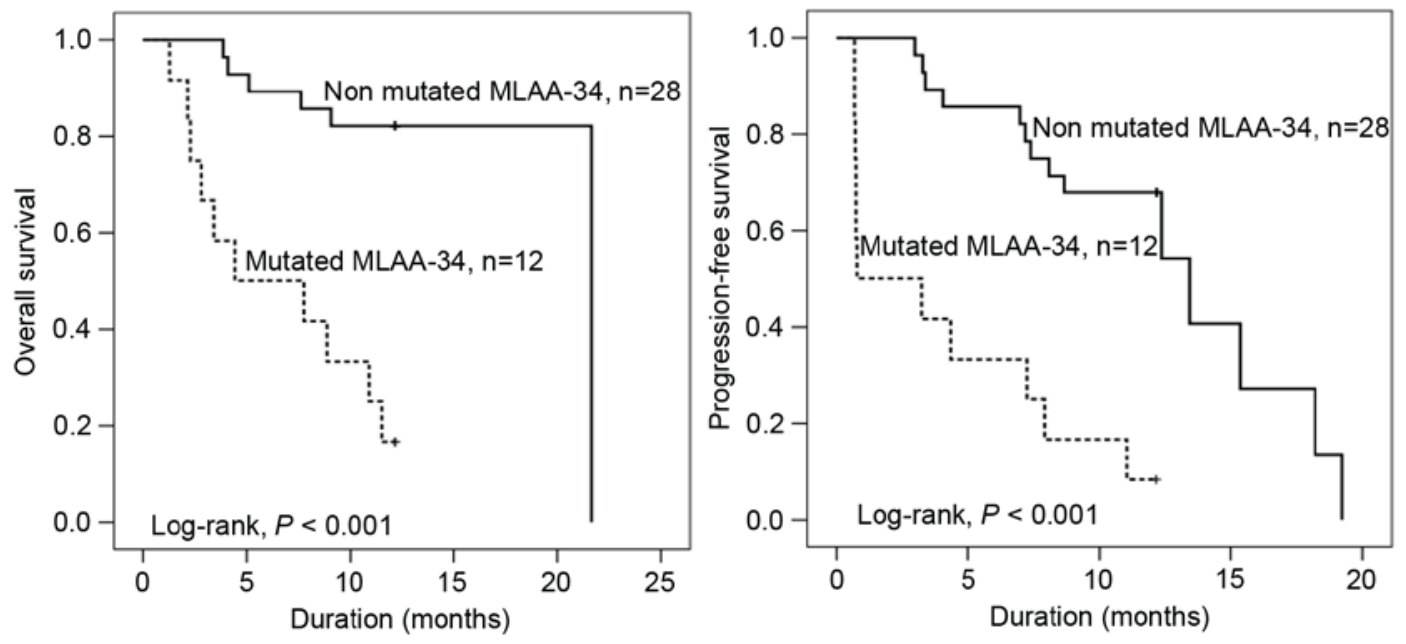

Figure 4. Kaplan-Meier overall survival, progression-free survival and survival rate curves of non-mutated MLAA-34 and mutated MLAA-34 patients in 40 patients with acute myeloid leukemia. In the survival rate curve, the numbers on the X-axis indicate survival months. MLAA-34, monocytic leukemia-associated antigen-34.

mutations, 9 patients were identified as high risk (HR) and 3 were identified as intermediate risk (IR). In 28 patients without mutation, 4, 19 and 5 were identified as HR, IR and low risk (LR), respectively (Table I). This CC/CT allele was located at the 59th bp of E2 of MLAA-34. Although this site belongs to the $5^{\prime}$ untranslated region, it is associated with MLAA-34 overexpression in patients with AML M5 (3). MLAA-34 was significantly upregulated in 12 E2-mutant $(+)$ patients with 
Table IV. Cox regression analysis of E2 mutation and extramedullary disease in patients with acute myeloid leukemia.

\begin{tabular}{lccccccc}
\hline & & & & & & \multicolumn{2}{c}{$95 \%$ CI for $\operatorname{Exp}(\mathrm{B})$} \\
\cline { 5 - 8 } Variables & $\mathrm{B}$ & $\mathrm{SE}$ & Wald & P-value & Exp(B) & Lower & Upper \\
\hline E2 mutation & 1.616 & 0.553 & 8.533 & 0.003 & 5.034 & 1.702 & 14.890 \\
Extramedullary disease & 1.819 & 0.675 & 7.257 & 0.007 & 6.165 & 1.841 & 23.155 \\
\hline
\end{tabular}

E2, exon 2; B, regression coefficient; SE, standard error; Wald, Wald test.

AML when compared with 28 E2-mutant (-) patients $(\mathrm{P}<0.01$; Fig. 3B). In addition, patients with AML containing E2 mutations usually had unfavorable therapeutic effects and were prone to recurrence (Table III).

MLAA-34 C59T mutation is associated with Flt3, DNMT3A mutations and other clinical features. Flt3 (14,15), DNMT3A (16), c-kit (13), CCAAT-enhancer-binding protein $\alpha$ (17) and nucleophosmin-1 (18) mutations represent the most frequent gene alterations detectable in AML. In order to know whether there are associations between MLAA-34 and these molecular markers, the mutations of these genes were analyzed by direct sequencing. MLAA-34 mutation in AML is associated with Flt3 and DNMT3A mutations $(\mathrm{P}<0.01$; Table III), but no apparent links between MLAA-34 and other markers were observed. In addition, mutation of MLAA-34 gene in patients with AML was associated with extramedullary disease, periphery leukocyte numbers, remission and cytogenetic abnormalities. Patients without this SNP site in MLAA-34 usually had a lower number of leukocytes $(\mathrm{P}=0.001)$, and indicated a relative higher percentage $(35.7 \%)$ of normal karyotypes, which means an increased success rate for hematopoietic stem cell transplantation treatment. No significant differences of MLAA-34 mutation were observed between males and females.

MLAA-34 C59T mutation indicates short OS, PFS and survival function. To assess the prognostic potential of the MLAA-34 C59T mutation in 40 patients with AML, additional analyses of OS, PFS and survival function were performed. The OS and PFS times of patients with MLAA-34 C59T mutation were significantly shorter when compared with that of patients without C59T mutations $(\mathrm{P}<0.001$; Fig. 4). The median OS times with MLAA-34 C59T mutation and without MLAA-34 C59T mutation were 4.4 and 21.6 months, respectively. The median PFS times with or without MLAA-34 C59T mutation were 0.8 or 13.4 months, respectively. In addition, the results revealed that E2 mutation and extramedullary disease indicated a significant association $(\mathrm{P}=0.333$ and $\mathrm{P}=0.007$, respectively). For relative risk $[\mathrm{RR}$; $\operatorname{Exp}(\mathrm{B})]$, the RR in patients with $\mathrm{AML}$ with E2 mutation was 5.034 times that of patients with AML without E2 mutation. In addition, the RR in AML with extramedullary disease was 6.165 times that of patients with AML without extramedullary disease (Table IV). For analyses of survival function, the survival rate (Cum survival) was lower in patients with E2 mutations compared with patients without mutation (Fig. 4).

\section{Discussion}

MLAA-34 is one of the newly identified monocytic leukemia-associated antigens $(11,19)$. This gene is homologous to the known human CAB39L gene and has been confirmed to be a novel splice variant of CAB39L $(5,9)$. The authors of the present study previously reported that MLAA-34 may act as an anti-apoptosis factor in vitro via interacting with Ras, Wnt or calcium and chemokine signaling pathways, and lentivirus-mediated ectopic expression of MLAA-34 in U937 cells markedly suppressed the spontaneous apoptosis of U937 cells $(5,12)$. Additional clinical studies uncovered that high MLAA-34 expression levels usually indicated unfavorable clinical features of patients with AML, and may be used as an early biomarker for detection of relapse $(5,9,12)$.

In the present study, it was revealed that MLAA-34 is upregulated in patients with AML when compared with healthy volunteers. A previous study reported that MLAA-34 was significantly induced in patients with acute monocytic leukemia (AML-M5), and MLAA-34 overexpression was associated with an unfavorable day 7 response to induction chemotherapy, and was also associated with a poor survival rate $(5,9)$. In addition, increased MLAA-34 levels were independently associated with poorer relapse-free survival and overall survival in patients with AML-M5 (9).

In attempt to uncover the mechanism of MLAA-34 overexpression, no gene translocation or copy number variance was identified. Finally, an SNP site was identified in the exon 2 of MLAA-34 when the gene was analyzed by DNA sequencing. Although this mutation site was located in the untranslated region, an association between the mutation and expression level of MLAA-34 was observed. In addition, MLAA-34 mutation was also associated with the molecular markers of AML, namely Flt3 and DNMT3A (20,21). However, the detailed underlying mechanism remains to be elucidated.

Regarding the prognostic potential of MLAA-34 C59T mutation in AML, it was revealed that MLAA-34 C59T mutation provided shorter survival durations for OS and PFS. In the present study, MLAA-34 C59T mutation was associated with extramedullary disease, periphery leukocyte numbers, remission and cytogenetic abnormalities. Studies have reported that these clinical lesions may result in shorter life for patients with AML $(22,23)$. For risk stratification, the HR was relatively increased in E2 mutation patients compared with patients without E2 mutation. This was in line with the RR in patients with E2 mutations. Thus, the survival rate was relatively lower in patients with E2 mutation compared with patients lacking E2 mutation. Therefore, MLAA-34 C59T mutation may 
indicate a risk recurrence and a prognostic factor for patients with AML.

E2 mutated positive in a total of 12 patients with AML-M5, potentially for the following reasons: in contrast to the other subtypes of AML, only a few leukemia-associated antigens have been characterized in patients of AML-M5, a distinct subtype of acute myeloid leukemia with characteristic clinical features (3); clinically, the disease is associated with hyperleukocytosis (5), extramedullary involvement (6), and coagulation abnormalities (7); and identification of immunogenic leukemia-associated antigens as target structures is mandatory for specific immunotherapy of AML-M5. For other FAB subsets and E2 mutations of the MLAA-34 gene, MLAA-34 mutation in patients with AML was associated with extramedullary disease, periphery leukocyte numbers, remission and cytogenetic abnormalities (Table III).

In conclusion, the evidence that the wild-type MLAA-34 is an anti-apoptotic factor $(12,24)$ and that overexpression of MLAA-34 was observed in patients with AML with poor response to standard chemotherapy indicated that MLAA-34 is a candidate oncogene. Thus, the present study shed light on the diagnosis and treatment of AML, and MLAA-34 may be a novel marker for AML therapy. This may be further demonstrated in the future by additional studies with a larger sample size.

\section{Acknowledgements}

The present study was supported by the National Natural Science Foundation of China (grant nos. 8153000580 and 81270597).

\section{References}

1. Lindblad O, Chougule RA, Moharram SA, Kabir NN, Sun J, Kazi JU and Rönnstrand L: The role of HOXB2 and HOXB3 in acute myeloid leukemia. Biochem Biophys Res Commun 467: 742-747, 2015

2. Stahnke B, Thepen T, Stöcker M, Rosinke R, Jost E, Fischer R, Tur MK and Barth S: Granzyme B-H22(scFv), a human immunotoxin targeting CD64 in acute myeloid leukemia of monocytic subtypes. Mol Cancer Ther 7: 2924-2932, 2008.

3. Tettamanti S, Marin V, Pizzitola I, Magnani CF, Giordano Attianese GM, Cribioli E, Maltese F, Galimberti S, Lopez AF, Biondi A, et al: Targeting of acute myeloid leukaemia by cytokine-induced killer cells redirected with a novel CD123-specific chimeric antigen receptor. Br J haematol 161: 389-401, 2013.

4. Mensen A, Oh Y, Becker SC, Hemmati PG, Jehn C, Westermann J, Szyska M, Göldner H, Dörken B, Scheibenbogen C, et al: Apoptosis susceptibility prolongs the lack of memory B cells in acute leukemic patients after allogeneic hematopoietic stem cell transplantation. Biol Blood Marrow Transplant 21: 1895-1906, 2015.

5. Zhang PY, Zhang WG, He AL, Wang JL and Li WB: Identification and functional characterization of the novel acute monocytic leukemia associated antigen MLAA-34. Cancer Immunol Immunother 58: 281-290, 2009.

6. Goswami M and Hourigan CS: Novel antigen targets for immunotherapy of acute myeloid leukemia. Curr Drug Targets 18: 296-303, 2017.

7. Sykes DB, Haynes MK, Waller A, Garcia M, Urso U, Gouveia KE, Sklar L, Lewis TA, Dandapani S, Munoz B, et al: Identifying small molecules that overcome differentiation arrest in acute myeloid leukemia. Oncologist 17: 3, 2012.

8. Greiner J, Döhner H and Schmitt M: Cancer vaccines for patients with acute myeloid leukemia-definition of leukemia-associated antigens and current clinical protocols targeting these antigens. Haematologica 91: 1653-1661, 2006.
9. Zhao J, He A, Zhang W, Meng X and Gu L: Quantitative assessment of MLAA-34 expression in diagnosis and prognosis of acute monocytic leukemia. Cancer Immunol Immunother 60: 587-597, 2011.

10. Kottaridis PD, Gale RE, Frew ME, Harrison G, Langabeer SE, Belton AA, Walker H, Wheatler K, Bowen DT, Burnett AK, et al: The presence of a FLT3 internal tandem duplication in patients with acute myeloid leukemia (AML) adds important prognostic information to cytogenetic risk group and response to the first cycle of chemotherapy: Analysis of 854 patients from the United Kingdom Medical Research Council AML 10 and 12 trials. Blood 98: 1752-1759, 2001.

11. Chen G, Zhang W, Cao X, Li F, Liu X and Yao L: Serological identification of immunogenic antigens in acute monocytic leukemia. Leuk Res 29: 503-509, 2005.

12. Zhang WJ, Zhang WG, Zhang PY, Cao XM, He AL, Chen YX and Gu LF: The expression and functional characterization associated with cell apoptosis and proteomic analysis of the novel gene MLAA-34 in U937 cells. Oncol Rep 29: 491-506, 2013.

13. Park IK, Mundy-Bosse B, Whitman SP, Zhang X, Warner SL, Bearss DJ, Blum W, Marcucci G and Caligiuri MA: Receptor tyrosine kinase Axl is required for resistance of leukemic cells to FLT3-targeted therapy in acute myeloid leukemia. Leukemia 29: 2382-2389, 2015.

14. Park SH, Lee HJ, Kim IS, Kang JE, Lee EY, Kim HJ, Kim YK, Won JH, Bang SM, Kim H, et al: Incidences and prognostic impact of c-KIT, WT1, CEBPA, and CBL mutations, and mutations associated with epigenetic modification in core binding factor acute myeloid leukemia: A multicenter study in a Korean population. Ann Lab Med 35: 288-297, 2015.

15. Sawyers CL: Finding the next Gleevec: FLT3 targeted kinase inhibitor therapy for acute myeloid leukemia. Cancer Cell 1: 413-415, 2002.

16. Berenstein R, Blau IW, Suckert N, Baldus C, Pezzutto A, Dörken B and Blau O: Quantitative detection of DNMT3A $\mathrm{R} 882 \mathrm{H}$ mutation in acute myeloid leukemia. J Exp Clin Cancer Res 34: 55, 2015.

17. Tawana K, Wang J, Renneville A, Bödör C, Hills R, Loveday C, Savic A, Van Delft FW, Treleaven J, Georgiades P, et al: Disease evolution and outcomes in familial AML with germline CEBPA mutations. Blood 126: 1214-1223, 2015.

18. Yoon JH, Kim HJ, Jeon YW, Lee SE, Cho BS, Eom KS, Kim YJ, Lee S, Min CK, Cho SG, et al: Outcome of allogeneic hematopoietic stem cell transplantation for cytogenetically normal AML and identification of high-risk subgroup using WT1 expression in association with NPM1 and FLT3-ITD mutations. Genes Chromosomes Cancer, 2015.

19. Fulton KM and Twine SM: Immunoproteomics: Methods and protocols. Methods Mol Biol. New York: Humana Press 1061: Springer. 2013

20. Yohe S: Molecular genetic markers in acute myeloid leukemia. J Clin Med 4: 460-478, 2015.

21. Annesley CE and Brown P: Novel agents for the treatment of childhood acute leukemia. Ther Adv Hematol 6: 61-79, 2015.

22. Chessells JM, Harrison CJ, Kempski H, Webb DK, Wheatley K, Hann IM, Stevens RF, Harrison G and Gibson BE; MRC Childhood Leukaemia working party: Clinical features, cytogenetics and outcome in acute lymphoblastic and myeloid leukaemia of infancy: Report from the MRC childhood leukaemia working party. Leukemia 16: 776-784, 2002.

23. Bolkun L, Lemancewicz D, Jablonska E, Szumowska A Bolkun-Skornicka U, Ratajczak-Wrona W, Dzieciol J and Kloczko J: The impact of TNF superfamily molecules on overall survival in acute myeloid leukaemia: Correlation with biological and clinical features. Ann Hematol 94: 35-43, 2015.

24. Qian L, Zhang W, Zhang P, Lei B, Wang X, Wang M, Bai J and He A: The anti-apoptosis effect of MLAA-34 in leukemia and the $\beta$-catenin/T cell factor 4 protein pathway. Am J Transl Res 7: 2270-2278, 2015. 